\title{
Utilização de metodologia multicritério para identificação de vetores concorrentes ao fomento de uma cultura de inovação organizacional
}

\section{Use of multicriteria methodology for identification of vectors competing to the promotion of an organizational innovation culture}

\author{
Rogério Henrique Ferreira Miranda ${ }^{1}$, Clodis Boscarioli ${ }^{2}$ \\ Recebido: 29/08/2020. Aceito: 23/10/2020
}

\begin{abstract}
Resumo
A estrutura de poder da empresa denominada aqui de $\mathrm{Alpha}^{3}$ é igualitária entre os dois países sócios; consequentemente, o processo decisório é binacional. Entretanto, inexiste na sua estrutura organizacional uma área responsável por pesquisa e desenvolvimento e, ademais, a melhoria de seus processos de trabalho ocorre de maneira quase empírica, sem muitas iniciativas formais para construir uma cultura de inovação. Este trabalho buscou identificar os vetores que concorrem para a criação de uma cultura de inovação corporativa por meio da metodologia multicritério de apoio à decisão e verificar a sua presença na Alpha. Realizou-se também pesquisa bibliográfica e pesquisa entre os empregados da empresa a fim de construir um referencial teórico que alicerçasse e validasse os vetores revelados pela metodologia multicritério, que foram: clima organizacional propício, educação corporativa voltada para a inovação, parcerias estratégicas e o estabelecimento de um prêmio corporativo de reconhecimento e recompensa. Os principais resultados alcançados denotam que existem na empresa Alpha iniciativas esparsas de desenvolvimento desses vetores, porém, ainda sem sinergia entre eles e sem a estruturação necessária para o estabelecimento de uma cultura de inovação efetiva na organização. Palavras-chave: Cultura de Inovação. Metodologia de Análise Multicritério. Melhoria de Processos.
\end{abstract}

\begin{abstract}
The power structure of company named here as Alpha is equal between the two partner countries; consequently, the decision-making process is binational. However, there is no research and development area in its organizational structure and, moreover, the improvement of its work processes occurs almost empirically, without many formal initiatives to build a culture of innovation. This work sought to identify the vectors that contribute to the creation of a culture of corporate innovation through the multicriteria methodology of decision support and to verify its presence in Alpha. Bibliographic research and research among company's employees were also carried out in order to construct a theoretical framework that would support and validate the vectors revealed by the multicriteria methodology, which were: favorable organizational climate, corporate education focused on innovation, strategic partnerships and the establishment of an award of corporate recognition and reward. The main results achieved show that there are sparse initiatives in the Alpha company for the development of these vectors, however, still lacking synergy among them and without the necessary structure for the establishment of an effective culture of innovation in the organization.
\end{abstract}

Key words: Culture of Innovation. Multicriteria Analysis Methodology. Process Improvement.

1 Mestre, Universidade Estadual do Oeste do Paraná - UNIOESTE, Foz do Iguaçu/Brasil. E-mail: rogeriohmiranda@hotmail.com 2 Doutor, Universidade Estadual do Oeste do Paraná - UNIOESTE, Cascavel/Brasil. E-mail: clodis.boscarioli@unioeste.br

3 Nome fictício adotado para se referir à organização alvo da pesquisa. 


\section{Introdução}

Há algum tempo discute-se a inovação como motor do crescimento econômico. É importante destacar, entretanto, que ela pode promover também o progresso em várias outras frentes, independentemente da situação econômica de um dado território, nação ou organização.

Trott (2012) observa que há uma tensão fundamental entre estabilidade e criatividade nas organizações. Se por um lado as empresas precisam de estabilidade para executar suas rotinas de trabalho, por outro necessitam desenvolver novas ideias e novos produtos para serem competitivas no futuro. Esse dilema ainda representa uma das grandes questões do mundo empresarial. Para Mattos e Guimarães (2013) as habilidades criativas aumentam e estimulam as habilidades de cada um, possibilitando novos padrões mentais para a abordagem de problemas, o que resulta, segundo eles, em uma ampliação do espectro de alternativas de resolução a serem consideradas e em um impacto positivo na produtividade e na qualidade do trabalho.

O processo de inovação, resultante da criatividade, é um dos instrumentos fundamentais nas estratégias de crescimento das empresas a fim de ampliar o seu poder mercadológico e proporcionar à organização vantagens competitivas. Por isso, gestores têm incentivado suas equipes a adotarem um comportamento inovativo.

Não basta, todavia, estar convicto da necessidade de inovar, é preciso saber como fazer acontecer e por onde começar.

O planejamento empresarial da Alpha é escalonado em missão, visão, valores e diretrizes fundamentais, objetivos estratégicos, diretrizes táticas e planejamento operacional e, ao longo dos anos a empresa foi reconhecida não somente como a maior geradora de energia limpa e renovável do planeta, com padrões de excelência em sua manutenção e operação, mas também se destacou pela atuação comprometida com a promoção da sustentabilidade. Em 2003, a missão da empresa foi ampliada tornando-a bastante diversificada.

Percebe-se daí, que a organização espera que a inovação seja considerada um valor intrínseco e está disposta a reconhecer os esforços dos empregados que se engajarem nesse propósito. Outro fato peculiar dessa instituição é que, por ser binacional, há culturas diferentes envolvidas no processo decisório. Não importa o programa a ser criado, este deve ser culturalmente aceito para que prospere, mesmo que seja um programa para mudar a cultura da própria empresa.

Entre as políticas e diretrizes fundamentais da entidade estão a proatividade e a inovação. A ênfase na sustentabilidade consta de seus objetivos estratégicos, o que remete ao compromisso de ter um corpo funcional envolvido com a inovação e com a melhoria contínua de seus processos de trabalho. Assim, uma forma de envolver e atingir todos estes aspectos é criar uma cultura de inovação mediante a melhoria de processos e, consequentemente, o que se espera como subproduto é aumento de produtividade, redução do desperdício, obtenção de fator de diferenciação, geração de novos negócios, incentivo à inovação incremental, diminuição da burocracia e construção de processos mais eficientes.

Doravante, as perguntas-problema que se apresentam quando se discute cultura de inovação são: Quais vetores concorrem à criação de uma cultura de inovação corporativa? Estão eles presentes na empresa? Ob- 
jetiva-se, de forma geral, discutir quais vetores concorrem à criação de uma cultura de inovação corporativa. Especificamente, identificar se a Alpha está, em alguma medida, em busca desses vetores para a criação de uma cultura de inovação organizacional.

Este artigo segue assim organizado: a seção dois traz o aporte teórico sob o qual a pesquisa se sustenta, a seção três apresenta o percurso metodológico trilhado, a seção quatro traz os resultados alcançados, na seção cinco tecemos as considerações finais e perspectivas da pesquisa.

\section{Referencial Teórico}

A transformação digital tem sido um desafio às corporações empresariais que vêm experimentando uma quarta revolução industrial. Ela, por sua vez, também é baseada na fusão de tecnologias que integram o físico, o digital e o biológico (SCHWAB, 2015). Essa integração desestabiliza empresas, mas, por outro lado, cria novas oportunidades impondo aos seus líderes a pressão constante de entender as mudanças, desafiar paradigmas e inovar para acompanhar essa transformação.

Ahmed (1998) ressalta a importância de analisar clima e cultura organizacional para inovação e analisa suas diferenças. O clima pode ser observado nas práticas e políticas organizacionais, enquanto que as crenças e valores que representam a cultura não podem ser assim notados por serem mais profundos. A cultura relaciona-se às interpretações feitas pelos empregados sobre as experiências vividas na organização "porque as coisas são do jeito que são e o modo e o porquê das prioridades organizacionais” (AHMED, 1998, p. 32).

Corroborando com a questão da complexidade que o tema da cultura organizacional impõe, Machado e Vasconcelos (2007) identificaram que a cultura de inovação é considerada como algo almejado nas organizações para a melhoria de seu desempenho e de sua vantagem competitiva. Nesse sentido, as pesquisas, de algum modo, validam tal associação, mas enfatizam, entretanto, a complexidade de fatores que envolvem a cultura de inovação.

Godoy e Peçanha (2009) investigaram a relação de cultura organizacional e de processos de inovação organizacional a partir de uma abordagem psicossociológica, e evidenciaram os seguintes aspectos da cultura organizacional relacionados à inovação: gestão estruturada dos processos de inovação; trabalho em equipe; suporte das lideranças; comunicação aberta; tolerância à ambiguidade; estímulo ao desenvolvimento de confiança; reconhecimento por todos da importância estratégica da inovação e abertura à exposição de ideias. Esse estudo demonstra a importância do papel das lideranças no estímulo a suas equipes para um olhar inovador, bem como o clima organizacional propício à apresentação de proposições por parte do corpo funcional sem a incerteza com relação ao eventual erro.

Tidd e Bessant (2015, p. 135-136) ensinam sobre a complexidade do conceito de cultura de inovação equiparável ao padrão de valores compartilhados, crenças e normas aceitas. Por sua vez Schein (1984) sugere que a cultura organizacional pode ser entendida em três níveis conectados e neste modelo fica claro que a gestão não pode mudar diretamente a cultura, mas pode intervir no nível dos artefatos, por meio da mudança das 
estruturas e processos e do fornecimento de modelos e de reforço dos estilos preferenciais de comportamento buscando uma cultura mais participativa. Frente a esses autores, vale afirmar que o sucesso em processos de inovação leva em consideração a criação de uma cultura organizacional em que estratégia, estrutura organizacional, comportamentos, mecanismos de reconhecimento e prêmios incentivem a criatividade (MARTINS; TERBLANCHE, 2003). O trabalho produtivo em equipe não acontece do nada, requer um clima que apoie a cooperação e a colaboração. Esse tipo de ambiente é caracterizado pela confiança mútua, em que todos se sentem confortáveis em discutir ideias e oferecer sugestões (TIDD; BESSANT, 2015, p. 110).

Porém, esses autores afirmam ainda que se deve conhecer e entender que cultura de inovação e clima organizacional voltados à inovação não partilham conceitos idênticos. Segundo eles a cultura se equipara a padrão de valores compartilhados, além de crenças e normas aceitas que moldam comportamentos. Clima, por sua vez, "envolve desenvolvimento de estruturas organizacionais, políticas de comunicação e procedimentos, como sistemas de reconhecimento e recompensa, política de treinamento, sistemas contábeis e de mensuração e desdobramento de estratégias" (TIDD; BESSANT, 2015, p. 135-136).

Assim, verifica-se que "o clima, portanto se distingue da cultura por ser mais perceptível em um nível mais superficial na organização e mais favorável a esforços de mudança e aperfeiçoamento" (TIDD; BESSANT, 2015, p. 141). Logo, observa-se que o clima organizacional tem uma influência direta no estabelecimento ou mudança da cultura de uma organização. Similarmente, segundo Arancibia et al. (2015), a cultura de inovação promove ações, normas, valores e atitudes estreitamente ligados à melhoria contínua e à criação de novos conhecimentos como marco de uma cultura organizacional sustentável e inovadora que permita gerar valor para a empresa e para o cliente. Por outro lado, esta tem sido definida também como um "contexto multidimensional que inclui a intenção de ser inovativo, a infraestrutura que dá suporte à inovação, comportamento de nível operacional necessário a influenciar o mercado e a orientação de valor e o ambiente para implementar a inovação" (DOBNI, 2008, p. 540).

Amabile (1988) lembra que ao contratar pessoas ou ao designar pessoal para a realização de algumas tarefas, é importante olhar não só para as habilidades que possuem, mas também para a sua motivação intrínseca, (sem apresentar, contudo, a razão de tal motivação). "As pessoas qualificadas que estão pessoalmente interessadas e desafiadas pela tarefa serão mais propensas a produzir trabalho criativo do que as pessoas qualificadas que não são tão motivadas" (1988, p. 163). A autora (1998) também relaciona o trabalho criativo a clima organizacional, defendendo uma atuação gerencial proativa. Segundo essa pesquisadora, a criatividade é uma função de três componentes: experiência, habilidades de pensamento criativo e motivação. Assim acredita que os gerentes podem influenciar esses componentes através de práticas e condições do local de trabalho.

Brem, Puente-Diaz e Agogué (2016) sob o viés da criatividade para a inovação apresentam três dimensões que influenciariam os ambientes organizacionais: o ambiente organizacional criativo, as competências de liderança relevantes para gerenciar essa criatividade e ferramentas, técnicas e métodos para estimular o pensamento criativo.

Um dos tópicos que povoam as mentes dos estudiosos sobre inovação é aquele referente ao processo 
inovativo ser aberto ou fechado, ou seja, se ele deve ser oriundo somente das pessoas que trabalham na organização, ou se seria possível e adequado se valer de parcerias com universidade, institutos de pesquisa ou até outras empresas congêneres.

Um exemplo de parceria que vem se construindo e se aprofundando ao longo do tempo é o existente entre a empresa e o Parque tecnológico de Alpha, criado em 2006. As duas instituições promovem trabalhos conjuntos no que diz respeito às inovações tecnológicas e já existem iniciativas em algumas áreas do conhecimento como no desenvolvimento de software, por exemplo.

Mas como a empresa pode obter colaboração da academia desprotegendo seus segredos e suas patentes? Esse paradoxo foi analisado por Gassmann, Enkel e Chesbrough (2010), que indica que as organizações devem tentar equilibrar atividades de inovação aberta e inovação fechada. Se por um lado as empresas protegem suas competências e propriedade intelectual (inovação fechada), o que significa que os processos de inovação são iniciados e gerenciados somente pelos empregados da organização, por outro precisam agilizar seus ciclos de inovação (inovação aberta), abrindo assim a possibilidade do estabelecimento de parcerias para alcançar esse objetivo.

No que diz respeito a prêmios de reconhecimento e recompensa, Barbieri et al. (2009) estudaram alguns sistemas de sugestões e observaram que eles têm o mérito de incentivar o empreendedorismo dos funcionários e com isso estimular o ambiente interno para as mudanças. Dessa forma, “os sistemas de sugestões podem ser propulsores de um processo para construir esse ambiente complexo que permite que a organização consiga um ritmo de produção sustentável de inovações” (BARBIERI et al. 2009, p. 309).

Brunt et al. (2012) creem que os prêmios induzem ao engajamento competitivo e que os maiores efeitos são para medalhas de prestígio. Por seu turno, Adler et al. (2015) analisaram os incentivos aplicados na faculdade de medicina da Universidade de São Francisco e concluíram que o financiamento levou a uma promoção acelerada, oportunidades de networking expandidas, maior conhecimento e habilidades, mais publicações e apresentações acadêmicas, recursos vindos de fora da Universidade e reconhecimento local e nacional. Outros autores que estudaram a questão dos prêmios nas corporações foram Frey e Gallus (2017), que sustentam que os prêmios são um fenômeno generalizado e advoga que eles atendem ao desejo fundamental de reconhecimento social e servem como um incentivo valioso para influenciar o comportamento.

\section{O Caminho Metodológico do Estudo}

Este artigo é resultante de uma pesquisa descritiva, bibliográfica e documental, de caráter qualitativo (MIRANDA, 2018), que considerou os aspectos fundamentais para a adoção de uma cultura de inovação, de maneira que se possa obter fundamentação bibliográfica para construir e propor um programa integrado com todos os principais eixos concorrentes e que se molde ao formato da instituição.

A análise multicritério de apoio à decisão (em inglês, Multicriteria Analysis Methodology - MCDA) é uma ferramenta que pode auxiliar em processos decisórios que precisam se pautar por critérios técnicos, ob- 
jetivos e transparentes, mas também por incorporar os juízos de natureza política e subjetiva dos envolvidos e de acordo com a situação específica. Pondera todas as partes envolvidas e compreende um amplo conjunto de abordagens que oferecem objetividade para determinar quais critérios ou assuntos são mais relevantes, julga também a importância atribuída a cada um deles e a melhor forma de utilizar essa informação dentro de uma estrutura complexa para avaliar as alternativas disponíveis (JANNUZZI et al., 2009).

Para descobrir os vetores que influenciam diretamente para a existência de uma cultura de inovação em uma determinada organização, utilizou-se a metodologia multicritério para apoio à tomada de decisão descrita em Roy (1996). Foram identificados quatro grupos (clusters) ou áreas de interesse que auxiliam na consecução do objetivo de criar uma cultura de inovação na organização alvo da pesquisa e que tem sustentação no referencial teórico, quais sejam, a existência de parcerias estratégicas, ambiente organizacional propício, prêmio de reconhecimento e recompensa e educação corporativa voltada à inovação.

Ensslin et al. (2001) argumentam que as metodologias de apoio à decisão numa pesquisa operacional se valem de modelos formais de resolução dos problemas que se propõe a tratar e que tais modelos podem ser quantitativos ou qualitativos. Segundo o autor, a forma de examinar o que está se modelando é bastante distinta nos paradigmas racionalista e construtivista.

As etapas necessárias à construção de um modelo multicritério em apoio à decisão que permitem avaliar as alternativas existentes, gerar novas alternativas e definir áreas de potencialidades que foram seguidas foram:

a) Identificação do contexto decisório que caracteriza o processo decisório em que o apoio à decisão irá ocorrer, bem como os atores que nele estão envolvidos e as ações alternativas a serem avaliadas;

b) Construção de mapas cognitivos para representação gráfica de como os decisores interpretam a situação decisória com que se defrontam. Na construção do mapa realiza-se um "brainstorming" com o decisor para a identificação dos elementos primários de avaliação (EPA) que permitirão o início da construção do mapa. Esses elementos são constituídos de objetivos, metas, valores dos decisores, ações, opções e alternativas (BANA e COSTA, 1992);

c) Análise dos mapas cognitivos que auxilia na estruturação de um modelo multicritério pela identificação de quais eixos de avaliação devem ser considerados no modelo multicritério. Esses eixos ou clusters formam um conjunto de nós relacionados de maneira muito estreita. Para cada cluster associa-se um nome que deve refletir o foco de interesse do decisor;

d) Pontos de vista fundamentais que mostram a transição de um mapa cognitivo para um modelo multicritério, através da identificação de um conjunto de Pontos de Vista Fundamentais, cujo conjunto deve obedecer a uma serie de propriedades;

e) Descritores que devem ser construídos para cada Ponto de Vista Fundamental, tal que permitam avaliar o desempenho das alternativas. Os descritores devem ser construídos em um processo interativo, com a participação do decisor. De maneira mais ampla, os descritores são uma parte da avaliação de desempenho e não podem ser dela dissociados. Eles são instrumentos de gestão utilizados para medir alguma propriedade do contexto. 
f) Funções de Valor, dado que, uma vez definido um descritor para cada Ponto de Vista Fundamental julga-se o quanto o desempenho de uma ação é atrativo, definindo-se, assim, uma função de valor associada, inserindo-se um critério de mensuração;

g) Taxas de substituição, tal que se possa determinar o desempenho global de cada ação, segundo o modelo de avaliação, determinando os pesos dos critérios;

h) Avaliação das ações: Uma vez definidos os parâmetros do modelo multicritério, é possível avaliar o desempenho de cada ação, visando compará-las entre si, podendo-se determinar ações de aperfeiçoamento para o sistema.

\section{Resultados e Discussão}

Primeiramente foram então definidos os agidos, que são aqueles que sofrem de forma passiva as consequências da implementação da decisão tomada, e os decisores, os representantes da empresa que irão avaliar se as ações resultantes do processo são efetivamente interessantes para a empresa e finalmente os facilitadores. Em seguida ao estabelecimento do rótulo iniciou-se a construção do mapa cognitivo através de brainstorming para a identificação dos elementos primários de avaliação. Esses elementos levaram à construção do mapa cognitivo, com o auxílio dos facilitadores. O agrupamento dos conceitos em áreas de preocupação tem como função reunir os conceitos criados tendo em conta os valores do decisor e o contexto que reveste o que se pretende alcançar. Cada área de preocupação recebe um nome que tem a responsabilidade de refletir da melhor forma possível o interesse principal do decisor (ENSSLIN et al., 2001).

Foram revelados então, como traz a Figura 1, os EPA associados em grupos que concorriam para o atingimento do rótulo estabelecido "a criação de uma cultura de inovação na Alpha". Mediante análise de documentos normativos da empresa, verificamos se esses quatro aspectos fundamentais que surgiram na análise multicritério (parcerias com stakeholders, clima organizacional, educação corporativa e prêmio de reconhecimento e recompensa) estão presentes na organização e em que grau. 
Figura 1 - Sistema de clusters para cultura de inovação

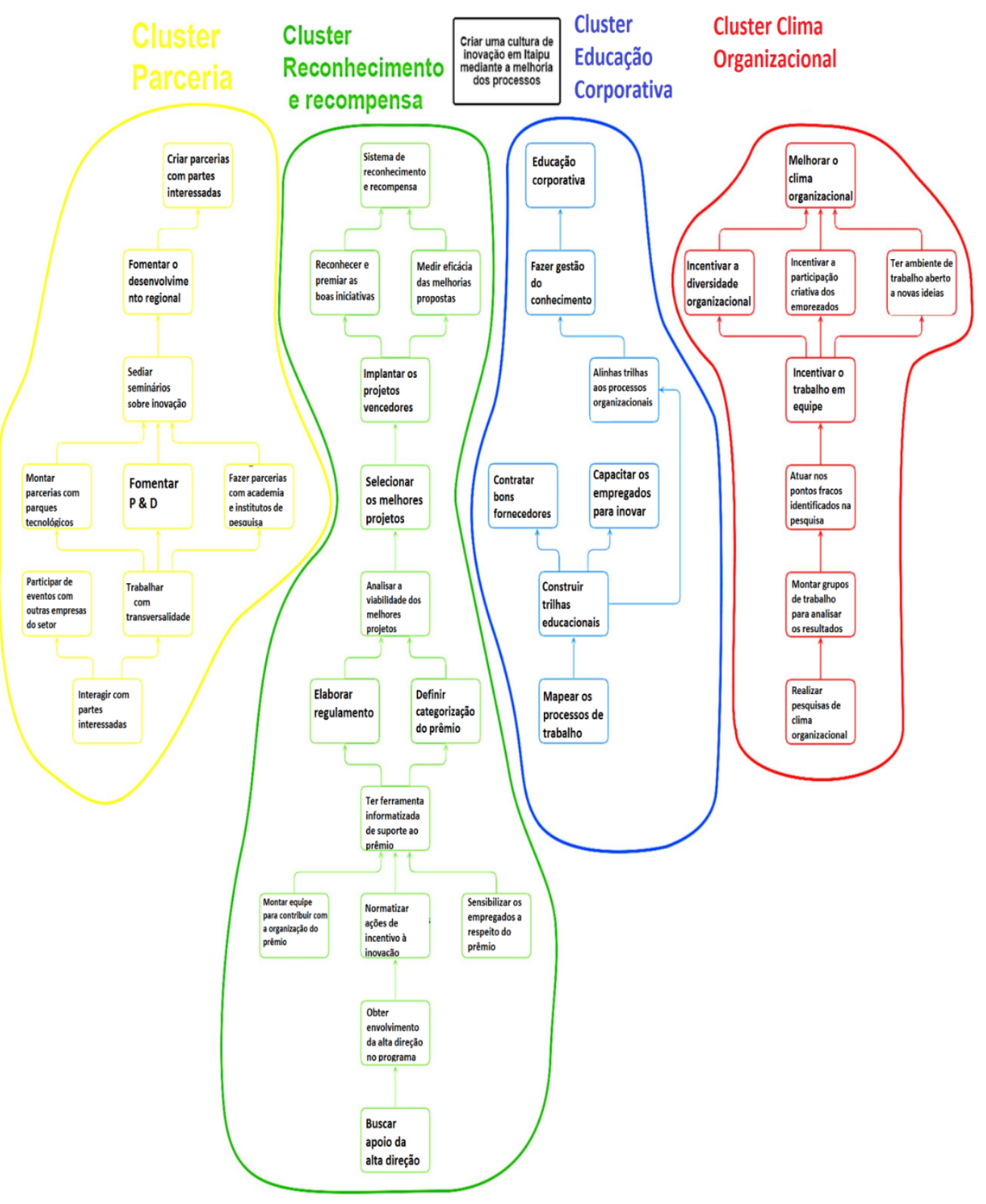

Fonte: Os autores, 2018.

A partir então da identificação dessas quatro vertentes procurou-se também identificar e compreender se estudiosos da cultura da inovação já haviam reconhecido tais aspectos como significativos ou até essenciais em uma organização que anseia possuir a tão buscada cultura da inovação, dado que para construir um programa de incentivo à inovação que se proponha a obter mudança cultural, essas áreas identificadas certamente devem ser trabalhadas no sentido de fazê-las presentes no dia a dia da organização, bem como integrá-las para que uma funcione como potencializadora da outra. Assim sendo, explica-se a seguir o estágio que cada uma se encontra na instituição investigada. 
Parcerias com partes interessadas: existem algumas parcerias em andamento na Alpha com a Fundação Parque Tecnológico de Alpha para a inovação, porém, na avaliação destes autores, há espaço para aprofundamento em algumas matérias.

Há oportunidades em parceiras na área de energias renováveis como o biogás, bem como na segurança de barragens, tecnologia da informação, pesquisas em hidrogênio entre outros temas. As ações envolvendo a parceria com a empresa de produção de biogás estão se revelando exitosas, o que demonstra que um aprofundamento nessas relações seria muito benéfico para solucionar um problema ambiental premente que são os dejetos oriundos de animais em confinamento existentes abundantemente na região de influência da empresa. Tais dejetos inevitavelmente vão se depositar no reservatório da hidrelétrica, o que é nocivo à qualidade da água e vida útil do próprio reservatório, tendo em vista a sedimentação e assoreamento.

Já existe uma parceria para o aproveitamento dos resíduos sólidos com a instalação da usina de demonstração na própria área da central hidrelétrica. A usina utiliza materiais orgânicos provenientes de corte de grama e resíduos dos refeitórios corporativos e os transforma em biogás, o qual é utilizado na frota de veículos da binacional, evitando assim o uso de combustíveis fósseis e sua consequente emissão de gases de efeito estufa na atmosfera.

As tecnologias envolvidas na fabricação de painéis fotovoltaicos estão em constante evolução. A Alpha, como empresa de geração de energia limpa e renovável, tem uma área de seu reservatório que poderia ser utilizada para abrigar tais painéis e assim, diversificar a geração energética se mantendo na sua missão de gerar energia limpa. Para isso, parcerias seriam, provavelmente, o caminho mais curto para a efetiva consecução de tal objetivo.

Apesar de abrigar um Parque Tecnológico com cursos universitários de universidades públicas parceiras a integração com essas instituições de ensino no sentido de integrá-las ao processo de inovação da empresa é ainda incipiente. Não há um programa estruturado de parcerias para inovação com as Universidades da região.

Educação Corporativa: a educação corporativa foi identificada como primordial no atingimento de um processo de mudança cultural para um padrão onde a inovação tenha papel de destaque. Em muitos aspectos, vetores da educação corporativa estão sendo desenvolvidos para que essa área seja protagonista em termos de mudança cultural na empresa. São eles:

a) Mapeamento de processos: a instituição vem sistematicamente mapeando seus processos de trabalho desde a identificação de sua cadeia de valor, passando pelos seus macroprocessos, processos e subprocessos até as tarefas que não podem mais ser estratificadas em subníveis. Esse trabalho se iniciou há poucos anos e está em fase de finalização;

b) Trilhas de aprendizagem: Murashima (2011) conceitua as trilhas de aprendizagem como um conjunto integrado e sistemático de ações de desenvolvimento que recorrem a múltiplas formas de aprendizagem, cujo objetivo é produzir conhecimento necessário ao desenvolvimento de competências, que engloba conteúdo teórico, habilidades e atitudes, necessárias para o desempenho das atividades do dia-a-dia profissional. Acredita-se que essas competências viabilizarão o alcance dos objetivos estratégicos da 
Entidade. O modelo de educação corporativa que está sendo desenvolvido vincula a aprendizagem em diferentes eixos temáticos combinando diversas técnicas de aprendizagem. A partir da identificação de seus processos nos mais diferentes níveis, a área de educação corporativa desenvolve as trilhas de aprendizagem visando a capacitar os empregados na direção dos processos identificados na fase anterior. A empresa também contou com o auxílio de uma consultoria especializada e o trabalho está quase todo finalizado;

c) Gestão do conhecimento: segundo Murashima (2011), o conhecimento gera vantagem competitiva por meio da inovação e, portanto, é um ativo, juntamente com vários outros elementos da organização, que constituem seu capital intelectual - um ativo intangível, comumente classificado como um capital não financeiro, entretanto, tal capital acaba por assumir um valor econômico quando possui valor para os clientes. Na empresa em questão, sua Universidade Corporativa é responsável pelo desenvolvimento de uma política estruturada de gestão do conhecimento, mas até o momento não há efetivamente um programa definido e identificado com esse fim;

d) Liderança: o desenvolvimento da liderança, por meio da educação corporativa, no sentido de incentivar o processo criativo da sua equipe, é primordial para estabelecer um processo empático com a equipe, bem como na motivação dos integrantes do time para atingir os objetivos corporativos. Existem iniciativas no sentido de capacitar as lideranças para exercer funções gerenciais, no entanto, não existe esse viés voltado para o incentivo à inovação.

Clima organizacional: segundo Serra, Fiates e Alperstedt (2007, p. 182) uma postura inovadora nem sempre é fácil, pois depende de um ambiente favorável, de pessoas criativas e sem medo de errar, de recursos para pesquisas e uma interação muito próxima com o mercado e seus atores, de modo a perceber as oportunidades existentes.

Por decisão administrativa, as pesquisas de clima organizacional não são mais realizadas desde 2013 e não houve um plano de ação para atuar nos pontos fracos detectados nas edições de 2008, 2010 e 2013 e, após as mudanças de diretoria ocorridas em março de 2017 e posteriormente em fevereiro de 2019, ainda não há uma diretriz sobre as pesquisas de clima organizacional e, consequentemente, sobre as ações que advêm da pesquisa.

Havia um esforço para um alinhamento estratégico entre direção, corpo gerencial e corpo funcional sendo construído com a participação de todos e capitaneado pelo diretor-geral brasileiro da entidade para que houvesse um direcionamento único dentro da organização. A questão da comunicação também vem sendo trabalhada para dar mais transparência às ações da diretoria. Foram criados ainda canais de comunicação entre os funcionários e o staff do diretor-geral, a fim de gerar uma aproximação ente esses dois polos e diminuir a distância entre graus hierárquicos. Essas iniciativas tomadas recentemente pela nova direção da Entidade certamente proporcionam um ambiente organizacional pacífico e propício ao engajamento com as metas empresariais, contudo, as pesquisas de clima seriam o indicador necessário para identificar eventuais pontos de gargalo existentes no clima da organização e, portanto, essenciais para direcionar ações pontuais. 
Sistema de Reconhecimento e Recompensa: Não há ainda uma gestão unificada e estruturada da empresa que trate sobre o tema inovação. O prêmio Alpha de incentivo à inovação que está sendo modelado é a única iniciativa corporativa nesse sentido.

\subsection{Uma pesquisa com empregados da Alpha}

Uma pesquisa foi realizada com empregados situados na hierarquia organizacional entre o nível estratégico e tático no mês de agosto de 2018, via Google forms, e teve como público-alvo os 168 empregados das áreas de planejamento, recursos humanos, responsabilidade social, energias renováveis, mobilidade elétrica e universidade corporativa. Desses, obtivemos como retorno 100 respostas. As perguntas tinham também como objetivo validar os clusters percebidos mediante a aplicação da metodologia multicritério ilustrados no Figura 1 e as respostas estruturadas com as seguintes opções: Discordo totalmente; Discordo em parte; Nem concordo nem discordo; Concordo em parte; e, Concordo totalmente.

O Gráfico 1 revela que o clima organizacional influencia no processo criativo pessoal e corporativo, dado que $90 \%$ dos respondentes acreditam em seu potencial motivacional, e o Gráfico 2 aponta que $81 \%$ dos respondentes creem que a educação corporativa desempenha um papel muito importante para a cultura de inovação corporativa.

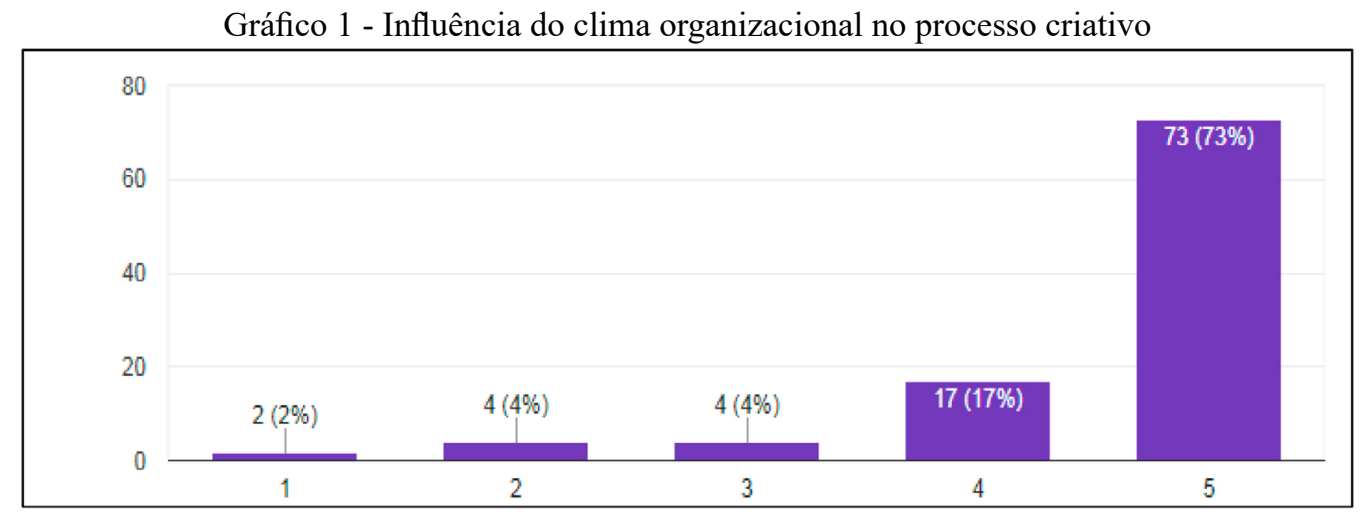

Fonte: Os autores, 2018.

Gráfico 2 - Contribuição da educação corporativa para uma cultura de inovação

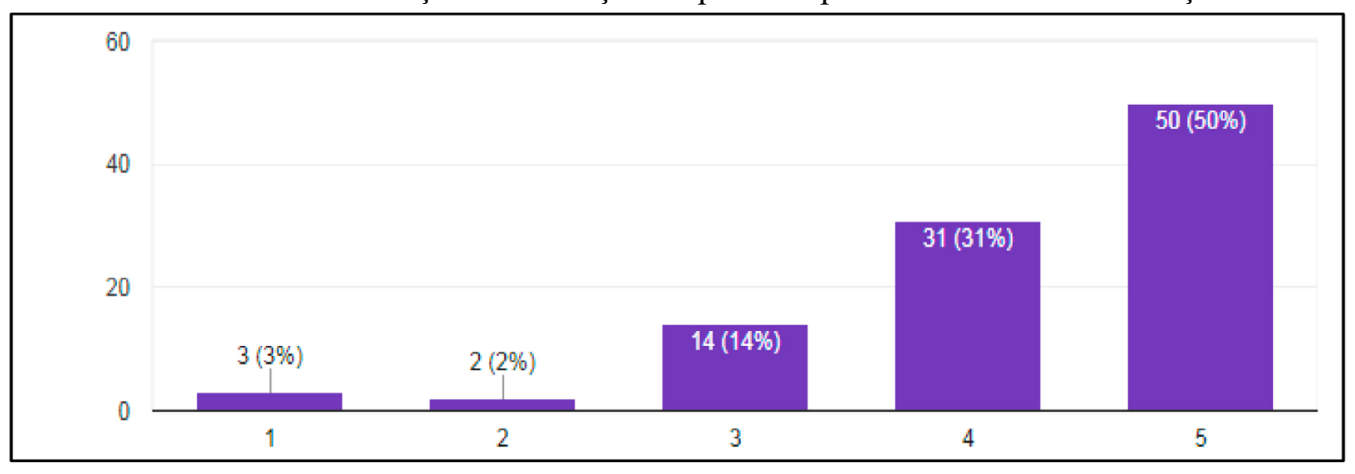

Fonte: Os autores, 2018. 
Em relação à influência da liderança (diretores e corpo gerencial) na motivação dos empregados para apresentarem propostas de melhoria nos processos de trabalho, $88 \%$ dos respondentes concordam que a liderança tem papel fundamental no estímulo aos funcionários quando o assunto é inovação, como ilustra o Gráfico 3.

Gráfico 3 - Influência da liderança para os empregados proporem melhorias nos processos

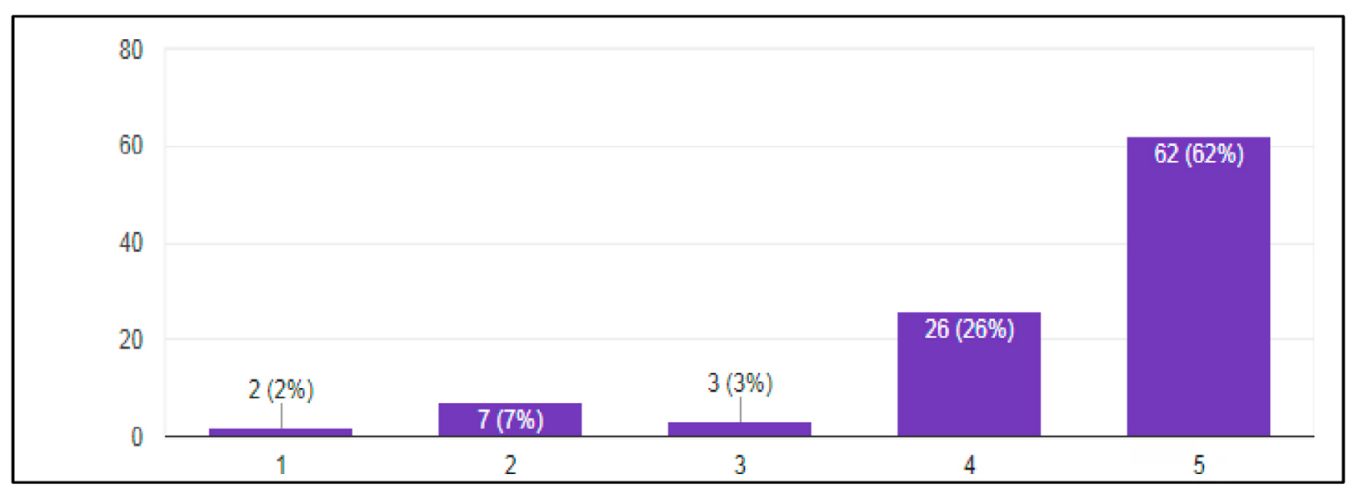

Fonte: Os autores, 2018.

Parcerias estratégicas com institutos de pesquisa, universidades e outras empresas congêneres impactam positivamente na cultura de inovação da organização. Na pesquisa realizada foi identificado que $78 \%$ concordam que parcerias estratégicas auxiliam na consecução de uma cultura de inovação na empresa.

Gráfico 4 - Grau de concordância sobre o papel positivo de parceiras estratégicas para inovação

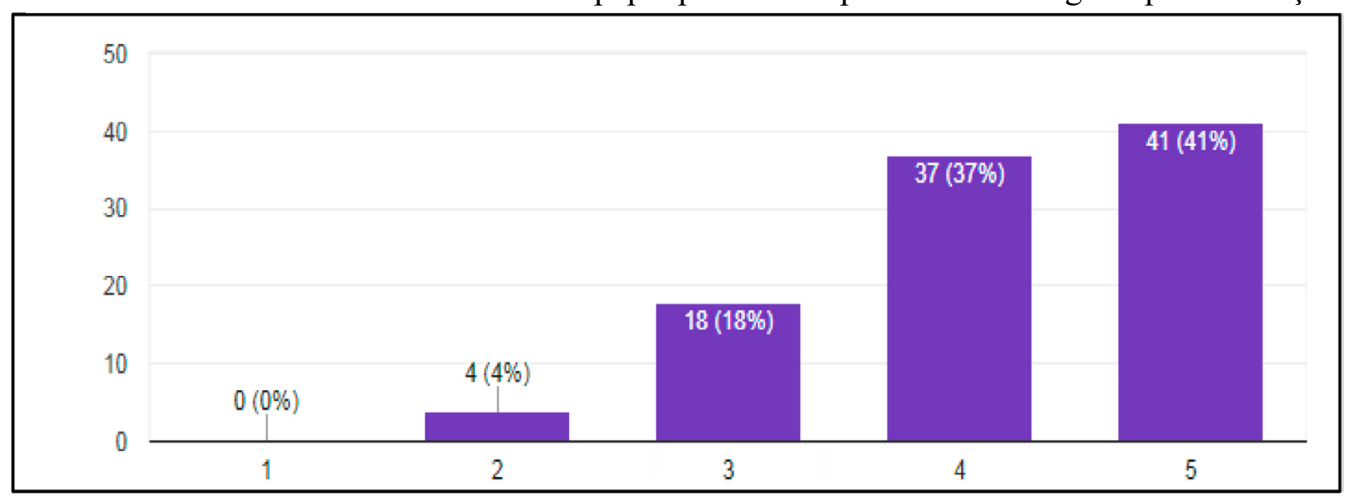

Fonte: Os autores, 2018.

Conforme demonstrado no Gráfico 5, 87\% concordam que um prêmio pode impactar positivamente no fomento de uma cultura de inovação na organização. 
Gráfico 5 - Impacto de um prêmio de reconhecimento e recompensa sobre a motivação dos empregados na apresentação de propostas de melhoria

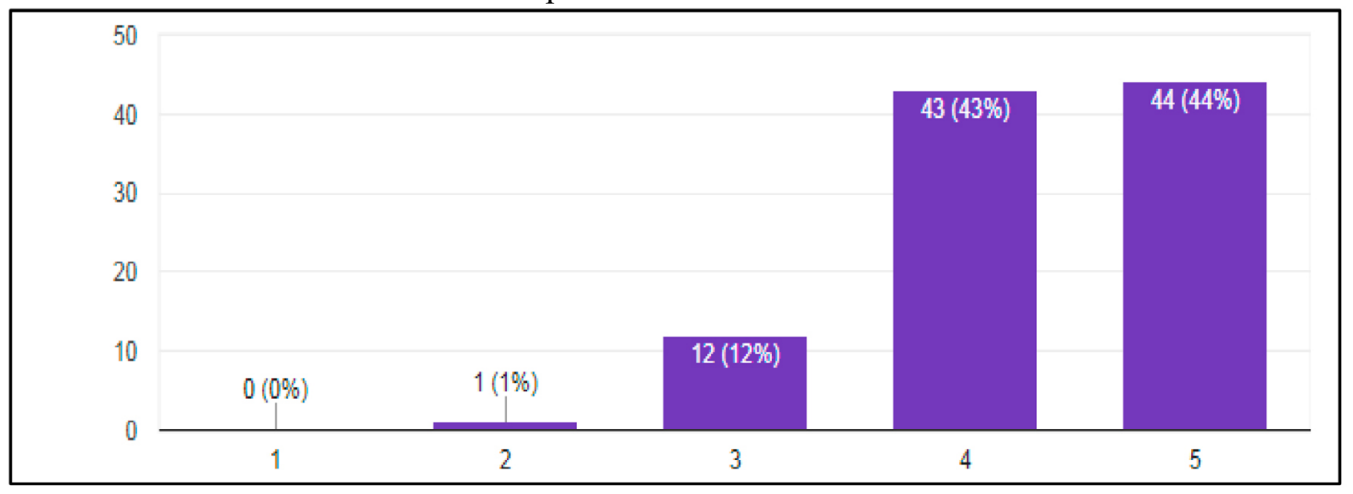

Fonte: Os autores, 2018.

A partir desses dados expostos verificou-se que estão validados os clusters identificados pela metodologia multicritério. A liderança tem um papel significativo na promoção de um ambiente propício a que os colaboradores apresentem propostas para a melhoria de seus processos de trabalho e inovações, sendo assim, a educação corporativa deve levar em conta, no seu programa de treinamento gerencial, princípios inerentes à promoção da inovação.

Na pergunta aberta sobre iniciativas corporativas relevantes para promover a cultura de inovação na empresa, colaboradores enfatizaram o papel da liderança na motivação dos empregados e promoção de uma cultura voltada para a inovação, sugeriram a criação de um espaço físico para a troca e compartilhamento de informações e ideias, recomendaram promover o empoderamento da Universidade Corporativa para que esta se torne a área responsável para cuidar da inovação e seus produtos derivados como registros, patentes, publicações e projetos de pesquisa, propuseram conciliar boas ideias e inovação com possibilidade de ascensão funcional e finalmente, apontaram repensar a estrutura funcional da empresa tornando-a mais flexível em aspectos como horário de trabalho flexível, ambientes mais descontraídos e acesso ilimitado à informação. Todas essas propostas merecem ser discutidas, analisadas em profundidade e avaliadas à luz do impacto que poderiam representar à construção da almejada cultura de inovação corporativa.

\section{Considerações Finais}

O estudo iniciou a estruturação do modelo a partir da contextualização do cenário, definição dos atores, do rótulo e do sumário, complementado com os levantamentos de elementos primários de avaliação e formulação de conceitos; e completado quando desenvolveu e desenhou as áreas de preocupação, os mapas cognitivos, os pontos de vista fundamentais e os descritores.

A metodologia foi escolhida por mostrar-se adequada para a distinção de vetores que favorecem o fomento de uma cultura de inovação em uma empresa complexa como a Alpha e, portanto, merecia uma avaliação que contemplasse diferentes ações e alternativas. Tendo em vista as vertentes resultantes da metodologia 
aplicada, confirma-se a proposição de que uma cultura de inovação não subsiste apenas com a criação de um prêmio de reconhecimento e recompensa, mas que deve necessariamente vir acompanhado de ações corporativas com o foco de, convergentemente com o prêmio, estabelecer a cultura de inovação na organização.

Nesse sentido, a educação corporativa se reveste de importância crucial para o alcance desse objetivo. O mapeamento dos processos empresariais, a criação das trilhas de aprendizagem e o processo de gestão do conhecimento bem estruturado podem ser o fiel da balança quanto ao sucesso ou não dessa iniciativa. Além disso, as lideranças devem ser capacitadas para motivarem suas equipes a empreender e trabalhar constantemente na melhoria de processos.

A identificação de parceiros e o estabelecimento de alinhamentos estratégicos no que diz respeito à inovação pode ser um diferencial no processo de integração entre empresa focal, institutos de pesquisa, parque tecnológico, academia, outras empresas do setor e eventuais parceiros da primeira camada de sua cadeia de suprimentos.

O monitoramento do clima organizacional da empresa é primordial para o sucesso da empreitada de fomentar uma cultura de inovação corporativa, pois as pesquisas de clima feitas periodicamente podem indicar se as ações tomadas nessa direção estão surtindo efeito ou não e a própria estrutura do Prêmio deve ser revista periodicamente e a sua efetividade avaliada, pois como foi identificado por Martin (2016), o próprio sistema de busca de ideias inovadoras necessita ser inovado periodicamente.

Sendo assim, acende-se uma "luz amarela" no sentido de que a Alpha necessita integrar esses aspectos aqui levantados - educação corporativa, clima organizacional, parcerias com stakeholders e prêmio de reconhecimento e recompensa - e que hoje se encontram esparsos, se a organização objetiva primordialmente ter sucesso na criação de uma cultura de inovação.

Vislumbra-se como trabalhos futuros investigar a forma como a educação corporativa e a gestão do conhecimento podem impactar positivamente no fomento de uma cultura inovativa nas organizações; o papel das lideranças na motivação de suas equipes para a constituição de equipes focadas na melhoria contínua de processos; métodos de reconhecimento e recompensa a colaboradores que demonstram entrega excepcional e auxiliam a empresa a atingir suas metas; e ainda, de que maneira as parcerias podem auxiliar no desenvolvimento de soluções para problemas ou dificuldades na melhoria de processos ou produtos da empresa sem que suas competências e recursos estratégicos sejam abertos aos concorrentes.

\section{Referências}

ADLER, S.R.; CHANG, A.; LOESER, H.; COOKE, M.; WANG, J.; TEHERANI, A. The Impact of Intramural Grants on Educators' Careers and on Medical Education Innovation. Academic Medicine: v. 90 Issue 6, p. 827-831, jun. 2015.

AHMED, P.K. Culture and climate for innovation. European Journal of Innovation Management, 1(1), 30-43, 1998. DOI: 10.1108/14601069810199131. Disponível em: https:/www.emerald.com/insight/content/ doi/10.1108/14601069810199131/full/html. Acesso em: 20 set. 2020. 
AMABILE, T.M. A model for creativity and Innovation in Organizations. Research in organizational behavior, v. 10, p. 123-167, 1988. Disponível em: http://web.mit.edu/curhan/www/docs/Articles/15341_Readings/Group_Performance/Amabile_A_Model_of_CreativityOrg.Beh_v10_pp123-167.pdf. Acesso em: 15 set. 2020.

AMABILE, T.M. How to kill creativity. Harvard Business Review 76, no. 5: p. 76-87, setembro 1998. Disponível em: https://hbr.org/1998/09/how-to-kill-creativity. Acesso em: 04 fev. 2020.

ARANCIBIA, C.S.; DONOSO, P.M.; VENEGAS, C.R.; CÁRDENAS, E.C. Identificación de Factores Clave en la Cultura de Innovación: El Caso de la Mediana Minería en Chile. Journal of technology management \& innovation, Vol.10(1), p. 132-145, 2015. Disponível em : https://scielo.conicyt.cl/scielo. php?script=sci_arttext\&pid=S0718-27242015000100010. Acesso em: 13 set. 2020.

BANA e COSTA, C.A. Structuration, Construction et Exploitation d'un Modèle Multicritère d'Aide à la Décision. IST, 1992. Disponível em: https://www.scienceopen.com/document?vid=ebc2607a-c57e-4474-b385-0cf4efa5b47c. Acesso em: 07 set. 2020.

BARBIERI, J.C.; ÁLVARES, A.C.T.; CAJAZEIRA, J.E.R. Geração de ideias para inovações: estudos de casos e novas abordagens. Revista Gestão Industrial UTFPR. ISSN 1808-0448 / v. 05, n. 03: p. 01-20, 2009. DOI: 10.3895/S1808-04482009000300001. Disponível em: https://periodicos.utfpr.edu.br/revistagi/article/ viewFile/418/309. Acesso em: 31 ago. 2020.

BREM, A.; PUENTE-DIAZ, R.; AGOGUÉ, M. Creativity and innovation: state of the art and future perspectives for research. International Journal of Innovation Management, v. 20, n. 7, 2016. Disponível em: http://www.worldscientific.com/doi/abs/10.1142/S1363919616020011. Acesso em: 18 set. 2020.

BRUNT, L.; LERNER, J.; NICHOLAS, T. Inducement prize and Innovation. The Journal of Industrial Economics. Volume 60, Issue 4, p. 657-696, Dez. 2012. Disponível em: https://www.hbs.edu/faculty/Publication\%20Files/11-118_089bff4b-868a-41f1-8f3d-351d1a58d2c2.pdf. Acesso em: 06 set. 2020.

DAS, G.S. Preparedness for innovation: an Indian perspective. Global Business Review, 4(1), p. 27-39, 2003. Disponível em: https://journals.sagepub.com/doi/10.1177/097215090300400103. Acesso em: 02 set. 2020.

DOBNI, C.B. Measuring Innovation Culture in Organizations: The Development and Validation of a Generalized Innovation Culture Construct Using Exploratory Factor Analysis. European Journal of Innovation Management 11(4), 539-559. Out. 2008. Disponível em: https://www.emerald.com/insight/content/ doi/10.1108/14601060810911156/full/html. Acesso em: 17 set. 2020.

ENSSLIN, L; MONTIBELLER NETO, G.; NORONHA, S.M. Apoio à decisão - metodologia para a estruturação de problemas e avaliação multicritério de alternativas. Florianópolis, Insular, 2001. Disponível em: https://www.worldcat.org/title/apoio-a-decisao-metodologias-para-estruturacao-de-problemas-e-avaliacao-multicriterio-de-alternativas/oclc/53850789. Acesso em: 22 set. 2020.

FREY, B.S.; GALLUS, J. Towards an Economics of Awards. Journal of Economic Surveys. v. 31 Issue 1. 
p. 190-200, fev. 2017. Disponível em: https://onlinelibrary.wiley.com/doi/abs/10.1111/joes.12127. Acesso em: 13 set. 2020 .

GASSMANN, O.; ENKEL, E. e CHESBROUGH, H. W. The future of open innovation. R\&D Management, v. 40, n. 3, 2010. Disponível em: https://www.researchgate.net/publication/227679791_The_Future_of_Open_Innovation. Acesso em: 10 set. 2020.

GODOY, R.S.P; PEÇANHA, D.L.N. Cultura organizacional e processos de inovação: um estudo psicossociológico em empresa de base tecnológica. Boletim Academia Paulista de Psicologia, 29(1), p. 142-163, 2009. Disponível em: http://pepsic.bvsalud.org/scielo.php?script=sci_arttext\&pid=S1415-711X2009000100012. Acesso em: 16 set. 2020.

JANNUZZI, P.M.; MIRANDA, W.L.; SILVA, D.S.G. Análise multicritério e tomada de decisão em políticas públicas: aspectos metodológicos, aplicativo operacional e aplicações. Revista Informática Pública, v. 11, n. 1, p. 69-87, 2009. Disponível em: https://www.researchgate.net/publication/228421871_Analise_Multicriterio_e_Tomada_de_Decisao_em_Politicas_Publicas_Aspectos_Metodologicos_Aplicativo_Operacional_e_ Aplicacoes. Acesso em: 08 set. 2020.

MACHADO, D.D.P.N.; VASCONCELOS, M.A. Organizações inovadoras: existe uma cultura específica que faz parte deste ambiente? Revista de Gestão USP, 14(4), p. 15-31, 2007. Disponível em: http://www.spell. org.br/documentos/ver/27606/organizacoes-inovadoras--existe-uma-cultura-especifica-que-faz-parte-deste-ambiente-. Acesso em: 08 set. 2020.

MARTIN, M. Inovação colaborativa em países emergentes: processo de geração de ideias. (Dissertação). Mestrado Profissional em Empreendedorismo, Universidade de São Paulo, Faculdade de Economia, Administração e Contabilidade, 116f, 2016. Disponível em: https://www.teses.usp.br/teses/disponiveis/12/12142/tde-21092016-111508/pt-br.php. Acesso em: 20 set. 2020.

MARTINS, E.; MARTINS, N. An organizational culture model to promote creativity and innovation. Journal of Industrial Psychology, 28(4), p. 58-65, 2016. Disponível em: https:/www.researchgate.net/publication/47739393_An_organisational_culture_model_to_promote_creativity_and_innovation. Acesso em: 15 set. 2020.

MARTINS, E.C.; TERBLANCHE, F. Building organizational culture that stimulates creativity and Innovation. European Journal of Innovation Management, v. 6, n. 1, p. 64-74, 2003. Disponível em: https:// www.emerald.com/insight/content/doi/10.1108/14601060310456337/full/html. Acesso em: 27 set. 2020.

MATTOS, J.R.L.; GUIMARÃES, L.S. Gestão da Tecnologia e Inovação. São Paulo: Saraiva, 2013.

MIRANDA, R.H.F. Uso de metodologia multicritério para modelagem de prêmio de reconhecimento e recompensa em Itaipu. 2018. 56 p. Dissertação (Mestrado Profissional em Tecnologias, Gestão e Sustentabilidade) - Universidade Estadual do Oeste do Paraná, Foz do Iguaçu, 2018.

MURASHIMA, M. Universidades Corporativas: as trilhas em meio a novos caminhos. Revista FGV Online, Rio de Janeiro, v. 1, n. 2, p. 4-23, abr. 2011. Disponível em: http://bibliotecadigital.fgv.br/ojs/index.php/ 
revfgvonline/article/view/19871/18796. Acesso em: 02 set. 2020.

ROY, B. Multicriteria Methodology for Decision Aiding. Dordrecht, Kluer Academic Publishers, 1996.

SCHEIN, E. Coming to a new awareness of organizational culture. Sloan Management review, Winter, v. 25, n. 2 p. 3-16, 1984. Disponível em: https://sloanreview.mit.edu/article/coming-to-a-new-awareness-of-organizational-culture/. Acesso em: 15 set. 2020.

SCHWAB, K. The fourth industrial revolution: what it means and how to respond. Foreign Affairs, 2015. Disponível em: https://www.weforum.org/agenda/2016/01/the-fourth-industrial-revolution-what-itmeans-and-how-to-respond/. Acesso em: 19 set. 2020.

SERRA, F.R.; FIATES, G.G.; ALPERSTEDT, G.D. Inovação na pequena empresa - estudo de caso na tropical Brasil. Journal of Technology Management \& Innovation, 2007. Disponível em: http://www.redalyc. org/articulo.oa?id=84720215. Acesso em: 04 set. 2020.

TIDD, J.; BESSANT, J. Gestão da inovação. 5. ed. Porto Alegre: Bookman, 2015.

TROTT, P. Gestão da inovação e desenvolvimento de novos produtos. 4. ed. Porto Alegre: Bookman, 2012. 